\section{Boosting Your Brain, Part 2: The Hard Way}

\author{
M. Castillo, Editor-in-Chief
}

l: my previous Perspectives, I enumerated several ways to exercise your brain and boost its capacity without expending too many calories or too much effort. You may recall that the results of such methods were controversial and minimally helpful at best. Before starting this vignette, I need to confess that I used to hate physical exercise. I remember failing the physical education courses in high school several times and spending long vacations in the library writing reports on the history of the Olympic Games to make up for my bad grades. When I turned 50 years of age, I made an appointment to see a doctor and was surprised at finding myself in the Geriatric Medicine Building. He recommended, as he does for all "senior" individuals, that I exercise, and now I do it regularly at least 4 times per week. Truth be told, I feel more attentive and even smarter if I do it before going to work.

Exercise makes us feel better physically and mentally, especially as we get older. In 1 study, the benefits of exercise were not affected by socioeconomic factors, presence of disease, body mass index, smoking, cohabitation, or disability and had clear benefits in elderly subjects compared with those who did not exercise. ${ }^{1}$ Cohabitation may be a stressful situation, and it has been shown that animals that are exercised regularly are better at living with other animals than those who are not. ${ }^{2}$ Although there are no human data to support similar benefits, it seems logical that we, too, would benefit in this regard. It is encouraging that one does not need to exercise strenuously to improve the brain. In older individuals, even light activities such as walking around the block, gardening, and cleaning are mentally beneficial. So perhaps there is some truth when people say that walking helps "clear their heads." Walking and staying active are said to change the dynamics of aging and to delay the onset of dementia by about 5-10 years. ${ }^{3}$ Weight-lifting, even light weights, has been shown by functional MR imaging to increase brain cortical activation. ${ }^{4}$

A recent article in Nature explains that exercise induces the process of autophagy. ${ }^{5}$ Autophagy is a lysosomal function that permits cells to recycle waste products and contributes to organelle and protein quality control. Autophagy protects not only against neurodegeneration but also against cancer, infections, aging, and insulin resistance. In lay language, cells become full of trash; and unless autophagy is turned on, they clog up and die. The contrary may also be true: If autophagy systems are genetically abnormal, no amount of exercise will improve one's health. In addition to exercise, starvation turns on this process and it is well-known that starved animals live longer. Lack of exercise may lead to obesity and result in development of adult-onset diabetes. In animals, only a significant amount of exercise will result in autophagy conferring a protective effect from developing diabetes. ${ }^{6}$ Diabetes is well-known to slow down the brain and lead to mental decline. This is particularly true if its onset occurs before 65 years of age, the disease duration is more than 10 years, it is the insulin-dependent type, and cerebral vascular complications

http://dx.doi.org/10.3174/ajnr.A3229 (leading to stroke) are present. Exercise and good diet are the 2 best ways to prevent obesity and diabetes.

Obesity affects the brain in many ways, even during infancy and teenage years. Obesity leads to faster bone and sexual maturation in both sexes, and its effects on brain maturation were recently studied. ${ }^{7}$ During healthy adolescence, there is considerable synaptic pruning and increased myelination, particularly in the frontal and parietal lobes. Obese teenagers show abnormalities in white matter, particularly affecting the orbitofrontal regions. This translates into lower brain volumes in those areas, behavioral disinhibition, and lower performance on cognitive tests independent of the presence of diabetes. It is intriguing that at least some types of fat may be disposed of in the absence of exercise. A study shows that in response to cold, brain activity increases and this leads to activation and usage of brown fat to maintain corporal thermogenesis. ${ }^{8}$ Because brown fat is available only in small volumes in only some parts of the body, even using it all up does not result in a significant weight loss nor does it protect from diabetes.

Muscles and brain power are generally not believed to go hand-in-hand, but the truth is that they do. Aerobics and running do great things for the brain. Weight-lifting increases the amount of brain-derived neurotrophic factor (BDNF), which sparks neurogenesis. The need to make split-second decisions during sports extends to everyday activities in most athletes. ${ }^{9}$ Also, exercise increases cerebral blood flow. In a study done by my colleagues here at the University of North Carolina, aerobic activity in elderly subjects was associated with lower arterial tortuosity and an increased number of small vessels, leading them to conclude that exercise may contribute to healthy brain aging. ${ }^{10}$

Human adult neurogenesis occurs in the dentate nucleus of the hippocampus, the subventricular zone, and the olfactory bulb and possibly also in the neocortex, striatum, amygdala, and substantia nigra. ${ }^{11}$ It is thought that as we age we produce fewer new cells in the hippocampi and that this contributes to cognitive decline. Experiments in elderly animals have shown that running increases hippocampal neurogenesis, which, in turn, is capable of reversing even fixed neurologic deficits that were present before exercising began. ${ }^{12}$ These authors concluded that voluntary exercise ameliorates some of the deleterious effects of aging. Not only does exercise foster hippocampal neurogenesis but increased local production of BDNF supports growth, development, maintenance, and survival of neurons there. Similar to a previously mentioned article, better arteries were found in the hippocampi of elderly humans who exercise, and animals forced to run demonstrated remarkable hippocampal angiogenesis in response to physical exercise. ${ }^{13} \mathrm{MR}$ imaging-generated maps of cerebral blood volume show increased perfusion to the hippocampi of humans who exercise, a finding opposite to that seen in patients with Alzheimer disease. ${ }^{14}$ Many fitness centers now offer aerobics for the elderly in programs called "elderobics," with the idea of promoting all of the above-mentioned benefits.

While exercising can improve your brain's performance, just thinking about muscle training can result in increased physical strength. In a fascinating study, subjects performing mental training of their hip flexors increased their strength by $24 \%$ compared with the $28 \%$ gained by actual exercise. ${ }^{15}$ These experiments have been repeated by different authors always reaching similar conclusions. Thus, just imagine what happens if you exercise and think about it, too! In the United States, nearly $50 \%$ of children 
between 12 and 21 years of age do not exercise, and less than $25 \%$ report getting 30 minutes of physical activity per day. ${ }^{16}$ Exercise by itself may not be enough to prevent mental deterioration because other factors such as smoking, hypertension, diabetes, obesity, low levels of education, and diet also play an important role.

In Part 1 of "Boosting Your Brain," I mentioned sex. In this regard, sex offers 2 benefits: exercise and a naturally rewarding activity, both of which have direct positive effects on the brain (at least studies in rats prove these benefits, and it is reasonable to believe that they extend to us humans). Conversely, negative stress suppresses adult neurogenesis. Rats that had daily sex for only 14 days showed new hippocampal neurons. ${ }^{17}$ Frequent sex induced continuous neuronal growth as well as growth of dendrites.

If exercising routinely is hard, just try dieting. The types of diet that exist are simply too many to consider here and are confusing (and outright bizarre, too; for example: the alkaline diet, lemonade diet, banana diet, and the purple food one). We know that a balanced diet is essential to maintain our brain's health. Antioxidants appear to directly benefit memory and are found mainly in flavonoids, which interact with BDNF and improve long-term potentiation. Like ginkgo biloba (see Part 1), flavonoids increase cerebral perfusion. Grapes, tea, cocoa, and blueberries are good for the mind. Ingesting glucose is also great, but only in moderate amounts; excessive glucose ingestion impairs brain function. ${ }^{18}$ Diets rich in fat also impair memory and affect the integrity of dendrites in the hippocampi. It has been postulated that fats promote an early onset of Alzheimer disease, whereas some types of fats, such as those found in fish oils, conversely may help prevent dementia. ${ }^{19}$ As mentioned before, starvation is good for the brain, whereas high-calorie diets promote neuronal dysfunction and degeneration. ${ }^{20}$

Recent data indicate that physical inactivity is linked to $21 \%$ of Alzheimer cases in the United States and 13\% worldwide. ${ }^{21}$ These numbers speak badly of our lifestyle here in the United States; but in Europe, only $40 \%$ of individuals exercise once a week and countries where citizens exercise the least often are Bulgaria, Greece, and Italy, with only $3 \%$ of their citizens exercising regularly. In contrast, $75 \%$ of Swedish and Finnish individuals exercise at least once per week. ${ }^{22}$ Asian countries also need their populations to exercise more; the Taiwanese are probably the least physically active in the entire world. ${ }^{23}$

Because many people exercise and then go to work and sit down all day long, most benefits from their initial physical activity will be cancelled out. Recent information indicates that regardless of exercising, if one sits more than 8 hours per day (typical for American adults), there is a $15 \%$ greater risk of dying in the following 3 years. ${ }^{24}$ This important observation makes one realize that after exercising, the rest of day needs to be filled with physical activities and not sedentary ones to preserve the benefits of the initial workout.

If you want to start exercising, experts tell you the following: keep it simple, 1 goal at a time and preferably a measurable one; develop motivation (as if keeping your mind sharp was not enough!); and report your progress to someone. Just think about this: If I was able to start doing it, so should you!

\section{REFERENCES}

1. Bertheussen GF, Romundstad PR, Landmark T, et al. Associations between physical activity and physical and mental health: a HUNT 3 study. Med Sci Sports Exerc 2011;43:1220-28

2. Reynolds G. Well. Why exercise makes us feel good. http://well. blogs.nytimes.com/2011/07/06/why-exercise-makes-us-feel-good/ ?scp $=3 \&$ sq $=$ why $\% 20$ exercise $\% 20$ makes $\% 20$ us $\% 20$ feel $\% 20$ better \&st $=$ cse. Accessed May 30, 2012

3. Reynolds G. Well. How exercise can keep the brain fit. http:// well.blogs.nytimes.com/2011/07/27/how-exercise-can-keep-thebrain-fit/?scp = 1\&sq = how $\% 20$ exercise $\% 20$ can $\% 20$ keep $\% 20$ the \%20brain\%20fit\&st=cse. Accessed May 30, 2012

4. Liu-Ambrose T, Nagamatsu LS, Voss MW, et al. Resistance training and function plasticity of the aging brain: a 12-month randomized controlled study. Neurobiol Aging 2012;33:1690-98

5. He C, Bassik MC, Moresi V, et al. Exercise-induced BCL2-regulated autophagy is required for muscle glucose homeostasis. Nature 2012;481:511-15

6. Reynolds G. Well. Exercise as housecleaning for the body. http:// well.blogs.nytimes.com/2012/02/01/exercise-as-housecleaning-for-thebody/? scp $=1 \& \mathrm{sq}=$ exercise $\% 20$ as $\% 20$ housecleaning $\% 20$ for \%20the\%20body\&st=cse. Accessed May 30, 2012

7. Cazettes F, Tsui WH, Johnson G, et al. Systematic differences between lean and obese adolescents in brain spin-lattice relaxation time: a quantitative study. AJNR Am J Neurodiol 2011;32:2037-42

8. Miao Q, Zhao XL, Zhang QY, et al. Stability of brain glucose metabolism following brown adipose tissue inactivation in Chinese adults. AJNR Am J Neuroradiol 2012;33:1464-69

9. Chaddock L, Neider MB, Voss MW, et al. Do athletes excel at everyday tasks? Med Sci Sports Exerc 2011;43:1920-26

10. Bullitt E, Rahman FN, Smith JK, et al. The effect of exercise on the cerebral vasculature of healthy aged subjects as visualized by MR angiography. AJNR Am J Neuoradiol 2009;30:1857-63

11. Sierra A, Encinas JM, Maletic-Savatic M. Adult human neurogenesis: from microscopy to magnetic resonance imaging. Front Neurosci 2011;5:47

12. van Praag H, Shubert T, Zhao C, et al. Exercise enhances learning and hippocampal neurogenesis in aged mice. $J$ Neurosci 2005;25:8680-85

13. Van der Borght K, Kobor-Nyakas DE, Klauke K, et al. Physical exercise leads to rapid adaptations in hippocampal vasculature: temporal dynamics and relationship to cell proliferation and neurogenesis. Hippocampus 2009;19:928-36

14. Pereira AC, Huddleston DE, Brickman AM, et al. An in vivo correlate of exercise-induced neurogenesis in the adult dentate gyrus. Proc Natl Acad Sci U S A 2007;104:5638-43

15. Singn G. Merely thinking about exercising can increase physical strength. http://www.examiner.com/article/merely-thinking-aboutexercising-can-increase-physical-strength. Accessed June 26, 2012

16. The human brain: renew-exercise. http://www.fi.edu/learn/brain/ exercise.html. Accessed May 30, 2012

17. Leuner B, Glasper ER, Gould E. Sexual experience promotes adult neurogenesis in the hippocampus despite an initial elevation in stress hormones. PLoS One 2010;5:e11597

18. Hall JL, Gonder-Frederick LA, Chewning WW, et al. Glucose enhancement of performance on memory tests in young and aged humans. Neuropsychologia 1989;27:1129-38

19. Puglielli L, Tanzi RE, Kovacs DM. Alzheimer's disease: the cholesterol connection. Nature Neurosci 2003;6:345-51

20. Memory improvement. Wikipedia. http://en.wikipedia.org/wiki/ Memory_improvement\#cite_note-42. Accessed May 30, 2012

21. Belluck P. Grasping for any way to prevent Alzheimer's. The New York Times. July, 25, 2011. http://www.nytimes.com/2011/07/26/ health/26alzheimer.html?_r = 1\&scp = 1\&sq=grasping $\% 20$ for $\% 20$ any $\% 20$ way\%20to\%20prevent $\% 20$ alzheimer\%27s\&st=cse. Accessed May 30, 2012

22. European Union. www.europa.eu. Accessed May 30, 2012

23. Official claims Taiwanese people least physically active. The China Post. September 19, 2011. http://www.chinapost.com.tw/taiwan/foreign-affairs/2011/09/19/317069/Official-claims.htm. Accessed May 30, 2012

24. Reynolds G. Well. Meet the active couch potato. http:// well.blogs.nytimes.com/2012/04/04/meet-the-active-couch-potato/ ?pagemode = print. Accessed May 30, 2012 